\title{
SEMICARBAZONAS E TIOSSEMICARBAZONAS: O AMPLO PERFIL FARMACOLÓGICO E USOS CLÍNICOS
}

\author{
Heloisa Beraldo \\ Departamento de Química, Universidade Federal de Minas Gerais, CP 702, 31270-901 Belo Horizonte - MG
}

Recebido em 31/7/03; aceito em 24/9/03

\begin{abstract}
SEMICARBAZONES AND THIOSEMICARBAZONES: THEIR WIDE PHARMACOLOGICAL PROFILE AND CLINICAL APPLICATIONS. This article shows that thiosemicarbazones, semicarbazones and their metal complexes can exhibit target selectivity along with a wide pharmacological profile. Complexes of thiosemicarbazones with cytotoxic or antitumoral activity are presented, some of which show activity against cisplatinum-resistant cells. The inhibition mechanism of the enzyme ribonucleoside diphosphate reductase (RDR), involved in DNA syntheses, by $\alpha(\mathrm{N})$-heterocyclic thiosemicarbazones is discussed. The encouraging results of clinical trials with the RDR inhibitor 3-aminopyridine-2-carboxaldehyde thiosemicarbazone ("Triapine") against rapidly growing tumors are outlined. Examples are also given of thiosemicarbazones with antiviral and antimicrobial activity. The possible applications of semicarbazones as anticonvulsants with low toxicity and good therapeutic index are presented.
\end{abstract}

Keywords: thiosemicarbazones; semicarbazones; pharmacological activity

\section{INTRODUÇÃO}

A atual Química Inorgânica Medicinal teve suas origens nos trabalhos de Paul Ehrlich, prêmio Nobel em Medicina e Fisiologia em 1908 e Alfred Werner, prêmio Nobel de Química em 1913, o primeiro a ser conferido a um químico inorgânico ${ }^{1}$. Ehrlich foi o fundador da quimioterapia e introduziu as primeiras idéias sobre relações estrutura-atividade e o conceito de índice terapêutico. Fez ainda uso de complexos metálicos, em especial os de arsênio, na preparação de drogas para o tratamento da sífilis ${ }^{2}$. Werner é considerado o pai da Química de Coordenação pelo desenvolvimento de sua teoria para explicar a estrutura e a ligação química nos complexos metálicos.

Apesar da grande importância dos trabalhos desses e de outros pesquisadores, a Química Medicinal dedicou-se, durante muitos anos, principalmente ao estudo de compostos orgânicos e produtos naturais. A investigação a respeito do uso de complexos metálicos como fármacos teve início, de modo sistemático, apenas após a descoberta feita pelo físico Barnett Rosemberg, da atividade antitumoral do cis(diaminodicloro)platina(II), o "cisplatina" ou cis-ddp, em $1965^{3}$. Desde então, uma imensa variedade de complexos metálicos foi e tem sido investigada quanto às suas propriedades terapêuticas. É interessante observar que o primeiro número da revista Metal-Based Drugs apareceu em 1994.

Tiossemicarbazonas e semicarbazonas (Figura 1) apresentam um amplo perfil farmacológico e constituem uma importante classe de compostos cujas propriedades têm sido extensivamente estudadas na Química Medicinal e, particularmente, na Química Medicinal Inorgânica, em razão de sua capacidade quelante e do papel da coordenação no seu mecanismo bioquímico de ação. Apesar da ampla versatilidade farmacológica desses compostos como uma classe, especificidades estruturais podem levar à manifestação de atividades específicas. Para os complexos metálicos, em alguns casos é possível modular a atividade através do desenho do ligante ou através da escolha do metal, como veremos adiante.

e-mail: hberaldo@ufmg.br

*Conferência proferida na 26a Reunião Anual da Sociedade Brasileira de Química, maio 2003, Poços de Caldas, MG. Trabalho dedicado à professora Lucia Tosi.

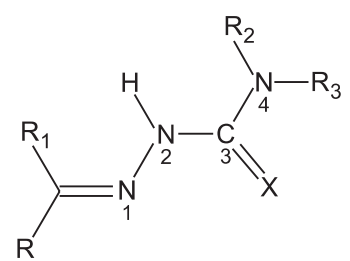

$$
\begin{aligned}
X & =S, O \\
R, R_{1}, R_{2}, R_{3} & =H, \text { grupos alquila ou arila }
\end{aligned}
$$

Figura 1. Estrutura genérica de semicarbazonas e tiossemicarbazonas.

De modo geral pode-se dizer que tiossemicarbazonas e semicarbazonas agem, seja como inibidores de enzimas, através da complexação de metais endógenos ou através de reações de redox, seja através de interações com o ADN e da inibição da síntese do ADN. Além disso, alguns complexos metálicos desses ligantes apresentam a habilidade de mimetizar a ação de certas enzimas.

Nesta revisão procuramos explorar algumas aplicações farmacológicas desses compostos e de seus complexos metálicos, discutindo mecanismos de ação, relações estrutura-atividade, usos clínicos e perspectivas futuras. Em um artigo anterior apresentamos um panorama geral de suas atividades ${ }^{4}$. No presente trabalho escolhemos discutir detalhadamente alguns aspectos que nos parecem mais significativos, tais como aqueles compostos que já se encontram em uso ou que estejam em fase de ensaios clínicos, ou aqueles para os quais haja uma perspectiva mais próxima de que se tornem candidatos a protótipos de fármacos.

\section{A VERSATILIDADE FARMACOLÓGICA DAS TIOSSEMICARBAZONAS}

Tiossemicarbazonas apresentam, entre outras, atividades como agentes antitumorais, antivirais, antifúngicos, antibacterianos e antimaláricos ${ }^{5}$. A atividade antitumoral tem sido sem dúvida a mais estudada. 


\section{TIOSSEMICARBAZONAS COM ATIVIDADE CITOTÓXICA OU ANTITUMORAL E SEUS COMPLEXOS METÁLICOS}

\section{Tiossemicarbazonas que agem como inibidores da enzima Ribonucleosídeo Difosfato Redutase (RDR)}

A atividade antileucêmica da 2-formilpiridina tiossemicarbazona (PT, Figura 2a) foi demonstrada já em $1956^{6}$, mas o composto apresentou baixo índice terapêutico. French e colaboradores ${ }^{7}$ formularam hipóteses a respeito do modo de ação de tiossemicarbazonas $\alpha(\mathrm{N})$-heterocíclicas e verificaram que esses compostos estariam atuando como agentes quelantes tridentados. Um aumento no caráter lipofílico, como na 1-formilisoquinolina tiossemicarbazona (IQ-1, Figura 2b), faz aumentar a atividade, com diminuição de toxidez. Verificou-se ainda que a ação antineoplásica só se manifesta em compostos nos quais a cadeia lateral se encontra em posição $\alpha$ com relação ao nitrogênio heteroaromático.<smiles>NC(=S)N/N=C/c1ccccn1</smiles>

(a)<smiles>NC(=S)N/N=C/c1ccc(O)cn1</smiles>

(c)<smiles>NC(=O)NO</smiles>

(e)

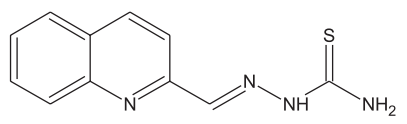

(b)<smiles>NC(=S)N/N=C/c1ncccc1N</smiles>

(d)

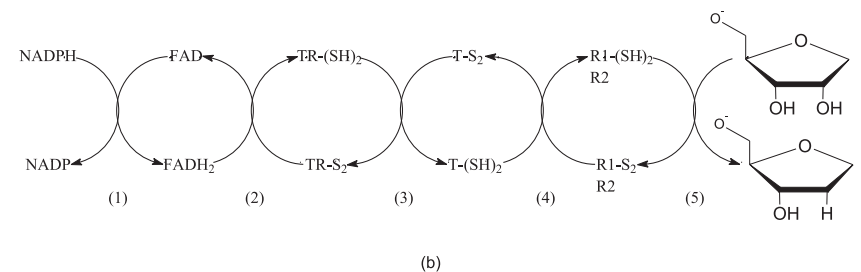

Figura 3. (a) Representação esquemática da estrutura da RDR; (b) ciclo de reações de oxi-redução envolvidas na conversão de ribonucleotídeos em desoxi-ribonucleotídeos, catalisada pela RDR (ver texto)

dos indicaram que o inibidor não interage no sítio da enzima que se liga aos nucleotídeos, mas foi encontrada uma correlação entre o bloqueio da ação enzimática e o substrato redutor ditiotreitol, usado como substituto do sistema natural tiorredoxina-tiorredoxina redutaseNADPH.

Este sistema faz parte do ciclo de reações redox envolvido na conversão de ribonucleotídeos a desoxirribonucleotídeos catalisada pela RDR, como mostrado na Figura 3b. No ciclo, os elétrons são transportados da nicotinamida adenina dinucleosídeo fosfato (NADPH) para o ribonucleotídeo através de uma cadeia envolvendo a flavoproteína flavina adenina dinucleosídeo (FAD), a tiorredoxina redutase (TR), a tiorredoxina $(\mathrm{T})$ e a $\mathrm{RDR}^{13}$. Tiorredoxina redutase, tiorredoxina e RDR contêm dissulfetos que participam das reações de transporte de elétrons. A tiorredoxina reduzida não cede diretamente um átomo de hidrogênio ao substrato, mas realiza antes a redução do dissulfeto da enzima. Mesmo fazendo parte do sítio enzimático, o grupo SH não reduz diretamente os ribonucleosídeos, mas interage antes com um outro intermediário ativado, que é o radical tirosila presente na estrutura da RDR.

Uma relação parcialmente competitiva entre IQ-1 e o substrato ditiol foi evidenciada, mostrando que o inibidor se liga no sítio ou próximo ao sítio da enzima normalmente ocupado pelo substrato. Uma vez que as tiossemicarbazonas são fortes agentes quelantes de ferro, imaginou-se que IQ-1 poderia exercer sua ação inibitória através da coordenação do metal presente na estrutura da enzima. No entanto esta suposição pareceria não se verificar, considerando-se, entre outros fatores, que o complexo de ferro de IQ-1 é melhor inibidor da síntese do ADN e da RDR do que o ligante livre, que a inibição da RDR por IQ-1 não é revertida pela adição de um grande excesso de ferro e que a inibição é revertida pela presença de quelantes do ferro. Como IQ-1 tem alta afinidade pelo metal, seria mais razoável supor que a forma ativa fosse um complexo de ferro, o qual se ligaria a um sítio normalmente ocupado pelo ferro e tióis, interrompendo assim a transferência de elétrons. Estudos realizados posteriormente com o complexo [Fe(IQ-1) $]$ indicaram que a forma ativa é o complexo de ferro(II $)^{11}$. Mais tarde Petering e colaboradores mostraram que as tiossemicarbazonas eram capazes de remover ferro da ferritina ${ }^{14}$ ou da transferrina ${ }^{15}$, indicando que estas poderiam ser as maneiras pelas quais esses compostos se ligariam ao ferro no organismo. 
Os mesmos autores relataram que, em uma série de tiossemicarbazonas $\alpha(\mathrm{N})$-heterocíclicas e seus complexos de ferro(II) e cobre(II), nenhum dos ligantes foi ativo contra células do tumor de Ehrlich, enquanto alguns complexos exibiam atividade. No entanto, tanto os ligantes quanto os complexos inibiam a síntese do ADN em concentrações mais baixas do que aquelas usadas nos testes de citotoxidez ${ }^{16}$. Além disso, os complexos de ferro de IQ-1, PT e 4-metil-5-amino1-formilisoquinolina tiossemicarbazona mostraram atividade três a seis vezes maior do que os ligantes livres como inibidores da RDR à qual não se havia adicionado ferro ${ }^{17}$ e o complexo de cobre de PT era um pouco mais ativo do que o ligante ${ }^{16}$. Esse complexo inibia o crescimento de células de Ehrlich e a síntese do $\mathrm{ADN}^{18}$.

O mecanismo de inibição da RDR de mamíferos pelo complexo de ferro de IQ-1 foi investigado por Thelander e Graslund ${ }^{19}$, que demonstraram que o alvo biológico da droga é o radical livre tirosila presente na sub-unidade $\mathrm{R} 2$, e que a tiossemicarbazona bloqueia a ação da enzima através da destruição do radical. A inibição requer a presença de oxigênio. Foi sugerido que o complexo de ferro(II) da IQ-1 reagiria com oxigênio molecular, com a conseqüente destruição reversível do radical.

Em nosso grupo, estudamos os complexos de ferro(II) e ferro(III) de tiossemicarbazonas $\alpha(\mathrm{N})$-heterocíclicas, com o objetivo de investigar mais detalhadamente o mecanismo de ação. Na preparação de complexos de ferro(III) a partir de cloreto férrico formava-se em torno de $20 \%$ de ferro(II $)^{20}$, sugerindo que o agente redutor deveria ser o próprio ligante, o qual tem a natureza de tiol. Assim, a cinética da redução dos complexos de ferro(III) por excesso do ligante foi investigada $^{21}$. A seguir verificamos que complexos de ferro(III) de tiossemicarbazonas podiam ser reduzidos por tióis-modelo de tióis celulares, tais como $\mathrm{N}$-acetil-L-cisteína e ditiotreitol, a primeira um modelo da glutationa e o último um modelo da tiorredoxina ${ }^{22}$. Propusemos então que o mecanismo de ação envolveria a oxidação do complexo de ferro(II) ao de ferro(III), com a liberação de um elétron que inativaria o radical livre da enzima, seguida da redução do complexo de ferro(III) ao de ferro(II) por um tiol celular.

Com base em nossos resultados outros autores investigaram o comportamento redox e a interação de $\left[\mathrm{Cu}(\mathrm{L})_{2}\right](\mathrm{L}=$ tiofeno-2carbaldeído tiossemicarbazona ${ }^{23}$ e de $\left[\mathrm{Fe}(\mathrm{L})_{2}\right] \mathrm{NO}_{3} .0 .5 \mathrm{H}_{2} \mathrm{O}$ e $\left[\mathrm{Cu}(\mathrm{L})\left(\mathrm{NO}_{3}\right)\right],(\mathrm{L}=\mathrm{PT})$ com glutationa na forma reduzida e 2mercaptoetanol, juntamente com suas atividades citotóxicas, e propuseram que a interação com os tióis estaria relacionada à citotoxidez desses complexos contra células de eritroleucemia de Friend e melanoma $\mathrm{B} 16 \mathrm{~F} 10^{24}$.

Até recentemente a 5-hidroxi-2-formilpiridina tiossemicarbazona (5-HP, Figura 2c) havia sido o único membro da classe das tiossemicarbazonas $\alpha(\mathrm{N})$-heterocíclicas a ser avaliado clinicamente. No entanto, a importante atividade antineoplásica observada in vitro e em animais não se verificou em pacientes com câncer, principalmente em razão da formação do metabólito $O$-glucuronídeo inativo, que é rapidamente eliminado ${ }^{25}$. Além disso, o composto mostrou menor afinidade pela RDR do que outros agentes como a IQ-1. A fraca atividade foi assim atribuída à pequena capacidade inibitória frente à enzima e à curta meia-vida biológica da droga, o que levou ao desenvolvimento de compostos de segunda geração que apresentassem maior afinidade pela RDR e que não fossem tão facilmente metabolizados.

Estudos de relações estrutura-atividade permitiram estabelecer estratégias de sínteses de derivados mais ativos como inibidores da RDR. O fato de que a atividade de IQ-1 é consideravelmente maior do que a de PT sugere a presença de uma interação hidrofóbica com a enzima, o que explica a maior atividade dos derivados 3-, 4- e 5metil-substituídos de PT. Para aumentar a afinidade pela RDR, o anel fenila hidrofóbico foi introduzido em várias posições na estru- tura de PT e o efeito dessas variações foi testado sobre a atividade da enzima de tumor de ratos. Os testes biológicos sugeriram que 2formil-4-( $m$-amino)fenilpiridina tiossemicarbazona possuía a combinação ótima de características estruturais, sendo o derivado mais ativo, tanto como inibidor do crescimento do tumor quanto da atividade da $\mathrm{RDR}^{26}$.

Na série das isoquinolinas o derivado 5-amino de IQ-1 exibiu capacidade de inibição da RDR similar a IQ-1, mas podia tornar-se solúvel sob a forma do sal ácido. O derivado 4-metil-5-amino-1formilisoquinolina tiossemicarbazona (MAIQ-1) foi então preparado para se obter (a) maior afinidade pelo alvo, (b) solubilidade em água como o sal ácido da amina (c) proteção estérica da função 5amino contra acetilação in vivo pela inserção do grupo metila volumoso (d) insensibilidade à O-glucuronidação, que é o destino metabólico de 5-HP em humanos. MAIQ-1 mostrou ser um excelente agente antineoplásico e um inibidor extremamente potente da RDR (60 vezes mais potente frente à enzima de hepatoma do rato do que 5 -HP e duas vezes mais forte do que 2-formil-4-( $m$-amino)fenilpiridina tiossemicarbazona $)^{27}$.

Desde então, uma grande variedade de tiossemicarbazonas heterocíclicas foram preparadas e avaliadas, que, por virtude de suas estruturas fossem resistentes à O-glucuronidação. Entre elas, 3- e 5aminopiridina-2-carboxaldeído tiossemicarbazona (3-AP e 5-AP) mostraram significativa atividade contra leucemia L1210 em ratos, sendo que o derivado 3-amino (Figura 2d) revelou ser o mais promissor. 3-AP mostrou-se seis vezes mais potente do que 5-HP como inibidor da atividade da CDP redutase e três e sete vezes mais potente como inibidor do crescimento de células de leucemia L1210 sensíveis e resistentes a 5-HP, respectivamente ${ }^{28}$.

Considerando-se que a $\mathrm{N}$-acetilação é uma reação metabólica in vivo e que derivados acetilamino de 3-AP e 5-AP mostraram-se inativos, compostos $\mathrm{N}$-alquilamino de 2-piridina carboxaldeído foram sintetizados, uma vez que a alquilação dos grupos amina do anel da piridina resulta na conversão de aminas primárias a aminas secundárias, as quais apresentam impedimento estérico à acetilação, além de fazer aumentar a lipofilia e possivelmente as propriedades farmacocinéticas desses compostos. Resultados de testes revelaram que esta modificação estrutural beneficia mais os derivados de 5-AP do que os de 3-AP.

O único inibidor de RDR em uso clínico é a hidroxiuréia (HUr, Figura 2e). No entanto, este composto é um fraco bloqueador da atividade da enzima e tem curta meia-vida no plasma, revelando-se um agente antitumoral de limitada eficácia. Outro problema é o surgimento de células tumorais resistentes, que envolveriam mudanças qualitativas ou quantitativas na $\mathrm{RDR}^{29}$.

As tiossemicarbazonas $\alpha(\mathrm{N})$-heterocíclicas encontram-se entre os inibidores mais potentes da atividade da RDR. A literatura traz excelentes artigos de revisão sobre inibidores desta enzima, em particular os da classe das tiossemicarbazonas ${ }^{30}$, as quais podem, sem dúvida, ser consideradas como os primeiros candidatos a substitutos da hidroxiuréia na clínica. De fato, muitas tiossemicarbazonas mostraram-se mais de mil vezes mais potentes como inibidores da RDR do que a hidroxiuréia. Entre os vários compostos da série, desenhados para atingir o alvo, 3-AP parece ser hoje o mais promissor, e encontra-se em ensaios clínicos fase II, realizados pelos laboratórios Vion, com o nome de "Triapina".

Alguns resultados obtidos da literatura para testes com 3-AP ${ }^{29}$ são mostrados na Tabela 1, que traz uma comparação dos efeitos de 3-AP e hidroxiuréia sobre o crescimento de culturas de células de leucemia L1210 e L1210 resistentes à hidroxiuréia. Como se vê, as células L1210 selecionadas para resistência à hidroxiuréia não exibiram um decréscimo correspondente na sensibilidade a 3-AP. 3-AP mostrou uma potência 65 vezes maior do que hidroxiuréia contra as 
células L1210 não resistentes e mais de mil vezes maior contra células resistentes. 3-AP foi também ativo contra L1210 de ratos em uma ampla faixa de concentrações, com capacidade de cura para alguns animais, sugerindo que poderia apresentar utilidade terapêutica.

Tabela 1. Efeito de 3-AP e hidroxiuréia (HUr) sobre o crescimento de células leucêmicas L1210 e L1210 resistentes à hidroxiuréia*

\begin{tabular}{lcc}
\hline & \multicolumn{2}{c}{$\mathrm{IC}_{50}(\mu \mathrm{M})$} \\
& $3-\mathrm{AP}$ & $\mathrm{HUr}$ \\
\hline L1210 & $1,3 \pm 0,5$ & 85 \\
L1210/HUr & $1,6 \pm 0,1$ & 2000 \\
\hline
\end{tabular}

*adaptada da ref.a 29

A redução de CDP a dCDP pela RDR foi inibida eficientemente por 3-AP com um valor de dose inibitória $\mathrm{IC}_{50}$ de $0,3 \mu \mathrm{M}$, ou seja, o composto é mil vezes mais potente do que a hidroxiuréia, com uma dose inibitória seis vezes menor do que a de 5-HP. Demonstrou-se ainda que 3-AP inibe seletivamente a incorporação de timidina marcada em L1210 e não a de uridina, sugerindo que sua ação seria através da inibição da síntese do ADN.

Apesar de que uma interação com o radical livre tirosila estabilizado pela presença de ferro esteja envolvida nos mecanismos de ação de 3-AP e da hidroxiuréia sobre a RDR, estes mecanismos não são idênticos, como indicado pelo fato de que o agente quelante desferal não aumenta a inibição por 3-AP, mas aumenta a inibição da síntese de $\mathrm{ADN}$ e do crescimento de adenocarcinoma 755 pela hidroxiuréia. Ao contrário, a inibição de RDR por 3-AP é praticamente abolida pela adição de desferal, como evidenciam os dados da Tabela 2. Os complexos pré-formados de 3-AP com ferro(II), ferro(III), cobre(II) e zinco(II) são melhores inibidores da CDP redutase do que o ligante e, com exceção do complexo de cobre(II), foram mais efetivos do que 3-AP contra o crescimento de células de leucemia L1210. Os complexos de ferro (II, III) foram mais efetivos do que os outros, confirmando que a forma ativa da droga é o complexo de ferro ${ }^{29}$.

Tabela 2. Efeito de desferal sobre a inibição da atividade de CDP redutase por 3 -AP*

\begin{tabular}{|c|c|c|}
\hline 3-AP $(\mu \mathrm{M})$ & Desferal $(\mu \mathrm{M})$ & $\begin{array}{c}\text { Atividade da CDP } \\
\text { redutase }(\mathrm{nmol} / 30 \mathrm{~min} / \mathrm{mg})\end{array}$ \\
\hline- & - & 12,2 \\
\hline 1,0 & - & 2,7 \\
\hline 1,0 & 100 & 11,2 \\
\hline
\end{tabular}

*adaptada da ref. 29

Tal como ocorre com a hidroxiuréia, os efeitos das tiossemicarbazonas sobre a proliferação celular são mais pronunciados quando as células encontram-se na fase $\mathrm{S}$ do ciclo e, assim, os cânceres mais sensíveis a estas drogas são aqueles de rápido crescimento, como as leucemias agudas ou leucemias crônicas. Para a aplicação de 3-AP a tumores sólidos, com fator de crescimento baixo, pode ser necessário o uso de combinações, levando-se em conta a habilidade do composto de atuar sinergisticamente com drogas que agem provocando danos no ADN, como etoposídeo, doxorrubicina, cisplatina e outras, já que 3-AP demonstrou ser capaz de inibir o reparo dessas lesões ${ }^{30}$.

Tanto quanto sabemos, até o presente não houve seleção de células cancerosas resistentes a 3-AP, seja em cultura, seja in vivo e assim não se sabe se células resistentes a 3-AP apresentariam resistência cruzada à hidroxiuréia. Alguns testes mostraram que 3-AP seria um substrato para a P-glicoproteína e para mrp ("multidrug resistance protein") ${ }^{31}$.

Mais recentemente foi demonstrada a atividade de 3-AP, usada sozinha, contra carcinoma $\mathrm{KB}$ de nasofaringe humano resistente à hidroxiuréia, contra o carcinoma de pulmão M109 de ratos e contra o carcinoma de ovário humano $\mathrm{A} 2780^{30}$. Foi também demonstrado que as células neoplásicas são mais sensíveis aos efeitos de inibição da síntese do ADN por 3-AP do que células normais, e que o tempo de recuperação da síntese do ADN em células normais é menor. Esta recuperação diferenciada dos tecidos constitui um importante princípio terapêutico requerido para o êxito da quimioterapia, na qual períodos de interrupção do uso do medicamento permitem a restauração dos tecidos normais. No caso de 3-AP, a recuperação mais rápida de tecidos normais seria possivelmente a base farmacológica do índice terapêutico da droga. É de interesse comentar ainda que 3AP foi capaz de cruzar a barreira hematoencefálica e inibir $95 \%$ do crescimento de células L1210 no cérebro ${ }^{30}$. Finalmente, em um artigo na revista Critical Reviews in Oncology/Hematology de 2002, Richardson sugere que novos estudos com 3-AP e outras tiossemicarbazonas certamente permitirão o desenvolvimento de agentes anticancerígenos eficazes ${ }^{32}$.

\section{Bis(tiossemicarbazonas) e seus complexos metálicos}

A atividade antitumoral de bis(tiossemicarbazonas) passou a ser amplamente investigada após a descoberta do potente efeito antineoplásico do composto 3-etoxi-2-oxobutiraldeído bis(tiossemicarbazona) (H2KTS) sobre tumores sólidos de ratos ${ }^{33}$. Demonstrou-se que a presença de cobre(II) era requisito essencial à atividade $^{34}$ e o complexo de cobre desse ligante (CuKTS) revelou-se um potente agente antitumoral ${ }^{35}$. Estudos de mecanismo de ação indicaram que CuKTS reagiria com tióis celulares em processos do tipo $\mathrm{Cu}$ (II)KTS $+2 \mathrm{RSH} \rightarrow \mathrm{Cu}(\mathrm{I}) \mathrm{RS}+1 / 2 \mathrm{RSSR}+\mathrm{H}_{2} \mathrm{KTS}$, que levariam à redução de cobre(II) a cobre(I), com o deslocamento do ligante. $\mathrm{O}$ cobre permanece dentro da célula e compostos que reagem com tióis inibem a reação, corroborando a hipótese de que os tióis celulares são os redutores. A síntese do ADN é inibida em 5 min, mas não se sabe se o agente citotóxico seria o cobre coordenado a um sítio ou o cobre como catalisador de reações de redox ${ }^{15}$.

Através do exame de uma série de bis(tiossemicarbazonas) verificou-se que o efeito citotóxico variava com a estrutura e que alguns desses ligantes eram ativados pelo íon zinco(II) ${ }^{36}$. Complexos de zinco(II) de 2,6-diacetilpiridina bis(tiossemicarbazonas) mostraram ação inibitória da proliferação e diferenciação de células de eritroleucemia de Friend (FLC) in vitro ${ }^{37}$. A citotoxidez de bis(tiossemicarbazonas) simétricas e assimétricas e de seus complexos de cobre(II), zinco(II), níquel(II) e cádmio(II) foi investigada em células tumorais humanas e de camundongos. Os ligantes e seus complexos apresentaram atividade citotóxica similar em leucemias e linfomas, mas nos tumores sólidos humanos as bis(tiossemicarbazonas) foram em geral menos ativas do que os complexos ${ }^{38}$.

Um artigo recente relata que um complexo de paládio(II) de benzil bis(tiossemicarbazona) poderia ter propriedades antitumorais importantes, já que apresenta valores de dose inibitória $\mathrm{IC}_{50}$ similares ao cisddp e mostra citotoxidez significativa contra células Pam-ras resistentes ao cisplatina. O complexo provoca mudanças conformacionais na estrutura do ADN diferentes daquelas induzidas pelo cis-ddp ${ }^{39}$.

\section{Complexos de tiossemicarbazonas com platina(II) e paládio(II)}

O interesse nos antitumorais de platina deveu-se à descoberta de Rosenberg de que complexos desse metal inibiam a divisão celular, sugerindo que poderiam ter atividade anticancerígena. $\mathrm{O}$ 
cis(diaminodicloro)platina(II) entrou em testes clínicos fase I em 1971 e foi aprovado para o tratamento de cânceres de ovário e testículo em 1978, sendo hoje uma das drogas mais usadas no tratamento desses tumores. O cisplatina contribui também para o tratamento dos carcinomas de faringe e cervical, linfoma, osteossarcoma, melanoma e neuroblastoma, entre outros. Desde então, milhares de complexos de platina foram avaliados como potenciais agentes antitumorais, em razão das desvantagens apresentadas pelo cis-ddp, tais como neurotoxidez, nefrotoxidez e o aparecimento de resistência ao medicamento $^{40}$.

A literatura recente apresenta estudos de complexos de paládio(II) e platina(II) com tiossemicarbazonas que se mostram ativos em células tumorais resistentes ao cisplatina, como os complexos de fenilacetaldeído tiossemicarbazona do tipo $\left[\mathrm{M}(\mathrm{HL}) \mathrm{Cl}_{2}\right], \mathrm{M}=\mathrm{Pd}(\mathrm{II})$, $\mathrm{Pt}(\mathrm{II})$, os quais são citotóxicos frente a uma variedade de linhagens tumorais, com um bom índice terapêutico e valores de concentrações inibitórias $\left(\mathrm{IC}_{50}\right)$ muito menores para células resistentes ao cisplatina (Pam-ras) do que para células normais (Pam) (ver Tabela 3). Além disso, ambos apresentam maior citotoxidez do que as drogas usadas clinicamente etoposídeo e adriamicina ${ }^{41}$. Estudos de mecanismo de ação, através da análise da interação dos complexos com o ADN, indicaram que os complexos formam principalmente ligações interfitas, ao contrário do cisplatina, que faz preferencialmente ligações intrafitas. O complexo de paládio(II) exibe maior atividade citotóxica sobre as células resistentes e forma mais ligações interfitas do que o análogo de platina(II), provavelmente em razão da maior reatividade do primeiro.

Tabela 3. Concentração inibitória $\mathrm{IC}_{50}$ obtida para fenilacetaldeído tiossemicarbazona e seus complexos de Pd(II) e Pt(II), cis-ddp, adriamicina e etoposídeo*

\begin{tabular}{lccc}
\hline & $\begin{array}{c}\mathrm{IC}_{50}(\mu \mathrm{M}) \pm \mathrm{sd} \\
\text { linhagem celular } \\
\text { PAM-RAS }\end{array}$ & HL 60 & PAM \\
\hline ligante & $84 \pm 1$ & $80 \pm 0,7$ & $128 \pm 5$ \\
complexo de Pt(II) & $65 \pm 1$ & $38 \pm 0,7$ & $200 \pm 9$ \\
complexo de Pd(II) & $23 \pm 0,2$ & $9 \pm 0,2$ & $124 \pm 3$ \\
cis-ddp & $157 \pm 6$ & $7 \pm 0,2$ & $164 \pm 6$ \\
adriamicina & $156 \pm 5$ & & $150 \pm 3$ \\
etoposideo & $136 \pm 10$ & & $180 \pm 12$ \\
\hline
\end{tabular}

*adaptada da ref. 41

Os mesmos autores mostraram que complexos binucleares de platina(II) e paládio(II) de $p$-isopropilbenzaldeído tiossemicarbazona apresentam igualmente atividade citotóxica contra diferentes linhagens de células tumorais e são ativos em células resistentes ao cisplatina, com bom índice terapêutico. Novamente os complexos fazem ligações inter-hélices ${ }^{42}$. Complexos desses ligantes contendo substituintes no nitrogênio terminal da cadeia apresentaram comportamento semelhante e pareceriam exercer atividade nas células resistentes através de indução de apoptose em baixas doses, abaixo daquelas necessárias para atingir as células normais, para as quais o mecanismo seria o de necrose $\mathrm{e}^{43}$. Muitos outros complexos de paládio(II) e platina(II) com tiossemicarbazonas diversas apresentaram comportamento similar.

Complexos de paládio(II) e platina(II) com 2-formilpiridina tiossemicarbazona de vários tipos estruturais, alguns dos quais obtidos pelo nosso grupo ${ }^{44}$, foram testados in vivo contra leucemia P388 de ratos ${ }^{45}$. A atividade antitumoral pareceria estar relacionada à facilidade de ataque redutivo dos complexos por tióis celulares. Complexos de paládio(II) de 2-acetilpiridina tiossemicarbazonas foram ativos in vitro contra leucemias P388 e L1210

\section{Complexos de tiossemicarbazonas com estanho(IV)}

Os primeiros estudos in vitro de atividade citotóxica de compostos organoestânicos foram feitos por Gielen e colaboradores, que mostraram que alguns desses compostos eram mais ativos do que cisplatina contra várias linhagens de tumores, entre as quais o tumor mamário MCF-7 e o carcinoma de cólon $\mathrm{WiDr}^{47}$. Há estudos que sugerem que o grupo $\mathrm{R}$ em compostos de tipo $\mathrm{R}_{2} \mathrm{SnX}_{2}$ determina a atividade citotóxica, sendo que o grupo n-butil pareceria ser aquele que confere maior atividade. A espécie $\mathrm{SnR}_{2}{ }^{2+}$ seria a forma reativa dentro da célula ${ }^{48}$.

Surge então a possibilidade de uma ação sinergística, pelo acoplamento de compostos diorganoestânicos com tiossemicarbazonas. Assim, os complexos [ $\left.\mathrm{SnMe}_{2}(\mathrm{~L})(\mathrm{OAc})\right] . \mathrm{HOAc}, \mathrm{L}=2$-formilpiridina tiossemicarbazonato, e $\left[\mathrm{SnPh}_{2}\left(\mathrm{~L}^{\prime}\right)\right] .2 \mathrm{DMF}$ e $\left[\mathrm{SnMe}_{2}\left(\mathrm{~L}^{\prime}\right)\right], \mathrm{L}^{\prime}=$ diacetilpiridina bis(tiossemicarbazonato), inibiram a proliferação de células de eritroleucemia de Friend (FLC), sendo que os melhores resultados foram obtidos com o composto contendo dois grupos fenila e aquele com dois grupos metila e um acetato ${ }^{49}$. No caso do primeiro composto, supõe-se que uma vez cruzada a membrana celular, ocorra hidrólise, a qual removeria o co-ligante acetato, restando a espécie $\left[\mathrm{SnMe}_{2}(\mathrm{~L})\right]^{2+}$, que seria aquela que atinge o alvo biológico. Supondo que a afinidade do acetato pelo cátion organoestânico poderia limitar a ocorrência de hidrólise, novos complexos diorganoestânicos do tipo $\left[\mathrm{SnR}_{2}(\mathrm{~L})\left(\mathrm{S}_{2} \mathrm{PPh}_{2}\right)\right]$ foram preparados, contendo 2-formilpiridina tiossemicarbazonato e o co-ligante difenilditiofosfinato. As atividades desses complexos sobre a proliferação e o crescimento de células tumorais FLC, K562, U937, TPM-1 foram testadas. Os melhores resultados foram obtidos com o derivado dibutil ${ }^{50}$.

Complexos diorganoestânicos de piridoxal tiossemicarbazona foram igualmente testados quanto à inibição in vitro da proliferação de eritroleucemia de Friend e os complexos dibutil e difenil mostraram ser os mais ativos. Estes mesmos compostos foram capazes de inibir completamente a síntese do ADN e, interessantemente, inibiram também a atividade da transcriptase reversa, o que sugere que poderiam ter igualmente atividade antiviral ${ }^{51}$.

A atividade citotóxica de tiofeno-2-carboxaldeído tiossemicarbazona e de seus complexos $\left[\mathrm{SnPh}_{2} \mathrm{Cl}(\mathrm{L})\right]$ e $\left[\mathrm{SnCl}_{2}(\mathrm{~L})_{2}\right](\mathrm{L}=$ ligante aniônico) foi testada contra adenocarcinoma de cólon humano, adenocarcinoma de mama, adenocarcinoma hepatocelular e leucemia linfoblástica aguda. O complexo contendo dois grupos fenila mostrou acentuada atividade ${ }^{52}$.

A baixa solubilidade dos complexos de estanho poderia ser contornada através do uso de ligantes hidrofílicos abandonadores, mas formulações requereriam o uso de suspensões coloidais. Enquanto a hidrólise do complexo parece ser necessária para a atividade, a lipofilia dos substituintes orgânicos estaria relacionada à citotoxidez, o que sugere que deveria haver um compromisso entre os dois fatores ${ }^{53}$.

\section{Tiossemicarbazonas e seus complexos com outros cátions metálicos}

As propriedades citotóxicas e antitumorais de muitas outras tiossemicarbazonas e seus complexos foram e continuam sendo investigadas, como relatamos em artigo anterior ${ }^{4}$. Aqui mencionaremos brevemente alguns estudos. Assim, complexos de cobre(II) de piridoxal tiossemicarbazona inibem células de eritroleucemia de Friend em ratos ${ }^{54}$ e complexos de cobre(II) de formiluracil tiossemicarbazona mostram-se capazes de inibir o crescimento de linhagens de leucemia humana K562 e CEM ${ }^{55}$. Alguns deles induziram apoptose celular. Tiossemicarbazonas derivadas de aldeídos naturais como citronelal, citral, octanal e octenal e seus complexos de cobre(II) e níquel(II) foram capazes de inibir o crescimento de célu- 
las U937, mas em geral não induziram apoptose celular in vitro ${ }^{56}$. Por outro lado, complexos de cobre(II) da tiossemicarbazona derivada de ácido $\alpha$-cetoglutárico induziram apoptose em linhagens de leucemia humana U937 e K56257, mas p-fluorobenzaldeído tiossemicarbazonas e um de seus complexos de níquel(II) apresentaram atividade inibitória significativa do crescimento de células U937 através de um mecanismo diferente do de apoptose ${ }^{58}$. Finalmente, um complexo de cobre(II) de 10-deacetilbacatin tiossemicarbazona, derivada do análogo de taxol 10-deacetilbacatin provocou a interrupção do crescimento do tumor de mama MCF- $7^{59}$.

Complexos de zinco(II) e cádmio(II) de 2-acetilpiridina tiossemicarbazona e de zinco(II) de $p$-isopropilbenzaldeído tiossemicarbazona exibiram valores de concentração inibitória $\mathrm{IC}_{50}$ na mesma faixa que o cisplatina em células sensíveis e resistentes ao cis-ddp, sendo mais ativos contra células resistentes ${ }^{60}$. O último apresentou atividade citotóxica contra células Pam-ras resistentes ao cis-ddp com um índice terapêutico in vitro de 3,26, versus 0,78 para o cisplatina. O tratamento de células Pam-ras (resistentes) com o valor de $\mathrm{IC}_{50}$ do complexo de zinco(II) induziu fragmentação do ADN genômico com um padrão de "escada", indicativo de apoptose, ao contrário do padrão "mancha", característico de fragmentação não específica do ADN genômico, observado em células Pam 212 normais.

Finalmente, caberia citar aqui publicações recentes que mostram que complexos de gálio(III) de tiossemicarbazonas apresentaram atividade antiproliferativa contra as linhagens de células tumorais humanas SW480, SK-BR-3 e 41-M ${ }^{61}$. Como sais de gálio são empregados clinicamente em pacientes portadores de alguns tipos de câncer $^{62}$, a idéia de aliar as propriedades terapêuticas das tiossemicarbazonas às do metal poderia constituir um caminho para o desenvolvimento de novas drogas.

\section{TIOSSEMICARBAZONAS COM ATIVIDADE ANTIVIRAL}

A procura por agentes antivirais teve início há mais de 50 anos, com a descoberta de que tiossemicarbazonas, introduzidas por Dogmak e colaboradores como agentes antituberculose ${ }^{63}$, eram ativas contra vaccinia vírus. Em 1950, Hamre et al. mostraram que benzaldeído tiossemicarbazonas eram ativas contra infecção por neurovaccínia vírus ${ }^{64}$. Em 1963 Bauer e colaboradores demonstraram que a N-metilisatina tiossemicarbazona (metisazona, Figura 4) era efetiva na profilaxia do vírus da varíola. O composto, comercializado com o nome de Marboran ${ }^{\circledR}$, foi empregado na profilaxia da varíola na Índia ${ }^{65}$ e, mais tarde, no tratamento de complicações resultantes da vacinação, mas apresenta efeitos colaterais pronunciados.

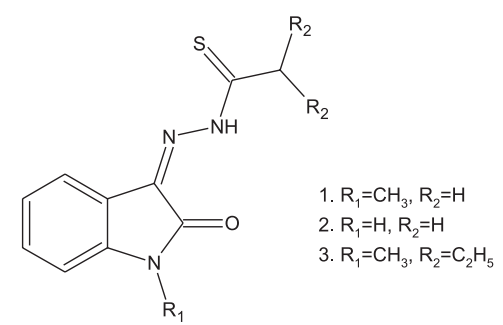

Figura 4. Estrutura genérica de tiossemicarbazonas derivadas da isatina, com atividade antiviral

Depois do êxito da vacina de varíola, o uso de metisazona foi interrompido. A Organização Mundial de Saúde (OMS) declarou a erradicação global da varíola em 1980. A subseqüente interrupção da vacinação tornou a maioria da população vulnerável à infecção. Após a erradicação da varíola, os países que dispunham de colônias do vírus deveriam tê-las destruído ou transferido os estoques para o "Center of Disease Control" em Atlanta, nos Estados Unidos, ou para o "State Research Center of Virology and Biotechnology (VECTOR labs)" em Koltsovo, na Rússia. No entanto, um comitê assessor da OMS para varíola definiu como muito importante o desenvolvimento de drogas para o tratamento do vírus, para a eventualidade do reaparecimento da doença causado pelo uso biológico ou terrorista desses estoques ${ }^{66}$.

Em artigo recente publicado na literatura sobre a história e as perspectivas da terapia e profilaxia de curto prazo de infecções virais, os autores sugerem que se faça o estudo do mecanismo de ação da metisazona e que se compare a eficiência desse composto com a de outros antivirais, como por exemplo o ciclofovir. Se a metisazona provar ser um agente seletivo, valeria a pena preparar novos análogos ${ }^{66}$.

$\mathrm{O}$ efeito antiviral de tiossemicarbazonas heterocíclicas derivadas de piridina, isoquinolina, purina e isatina em herpes simplex vírus (HSV) foi examinado por Brockman e colaboradores, que estabeleceram que somente os compostos em que a cadeia lateral se encontra em posição $\alpha$ com relação ao anel heteroaromático eram ati$\operatorname{vos}^{6,67}$. Mais tarde foi demonstrado que tiossemicarbazonas derivadas de 2-acetilpiridina, 2-acetilquinolina e 1-acetilquinolina eram ativas contra HSV in vitro e em um modelo in vivo de herpes cutâneo ${ }^{68}$. Além disso, foi mostrada a atividade de derivados dialquil-substituídos da N-metilisatina tiossemicarbazona contra o vírus da leucemia Moloney, um membro da família dos retrovírus ${ }^{69}$. Recentemente, um estudo de relações estrutura-atividade de uma série de tiossemicarbazonas $\alpha(\mathrm{N})$-heterocíclicas estabeleceu relações entre a atividade e alguns parâmetros físico-químicos ${ }^{70}$.

Vírus usam poucas enzimas em seu ciclo vital, tornado-as alvos atraentes para a quimioterapia ${ }^{71}$. Tiossemicarbazonas derivadas de 2-acetilpiridina mostraram-se ativas como inibidores da RDR de mamíferos. A infecção por herpes simplex vírus induz a formação de uma RDR única, a qual, ao contrário da RDR dos mamíferos, é livre de controle alostérico. Há evidências de que a RDR induzida por vírus é composta de duas sub-unidades não idênticas, H1 e H2, que são diferentes das sub-unidades R1 e R2 da enzima dos mamíferos. $\mathrm{O}$ fato de as enzimas serem bioquimicamente distintas sugere que elas poderiam ser afetadas diferentemente por inibidores e, assim, a RDR do vírus seria um alvo para as drogas antivirais. De fato, foi demonstrado que a enzima do vírus é mais sensível à inibição por tiossemicarbazonas derivadas de 2-acetilpiridina do que a enzima celular homóloga ${ }^{72}$. Por outro lado, há evidências de efeitos tóxicos nas células nas concentrações usadas para inibir o vírus, o que põe em dúvida a seletividade dessas drogas ${ }^{73}$.

A inibição da RDR em geral leva à redução da concentração intracelular de desoxiribonucleotídeos. Assim, análogos de nucleotídeos, que são efetivos antivirais através da competição com os nucleotídeos naturais, poderiam ter sua eficácia aumentada pela presença de tiossemicarbazonas. Uma série de tiossemicarbazonas derivadas de formil e acildiazinas foi testada quanto à atividade citotóxica e à atividade frente a herpes simplex vírus (HSV) e o vírus da imunodeficiência humana (HIV) ${ }^{74}$. O efeito da combinação desses compostos com as drogas antivirais aciclovir (ACV) e 3'-azido-3'desoxitimidina (AZT) foi igualmente avaliado. Nas condições dos experimentos não houve evidências para atividade antiviral, mas as tiossemicarbazonas mostram um amplo espectro de efeitos citotóxicos. Foi observado também um sinergismo moderado dos derivados não citotóxicos com o aciclovir e o $\mathrm{AZT}^{74}$.

Um outro trabalho ${ }^{75}$ demonstra que $N$-metilisatina- $\beta-4^{\prime}: 4^{\prime}$-dietil tiossemicarbazona e N-alil-isatina- $\beta-4$ ': 4 '-dialil tiossemicarbazona (Figura 4) bloqueiam a produção de HIV, como confirmado através da inibição da atividade da transcriptase reversa. Índices terapêuticos de 20 e 30, respectivamente, foram encontrados, bem como uma inibição seletiva da síntese de proteínas estruturais do vírus. Nas mes- 
mas concentrações não houve evidência de efeito das tiossemicarbazonas sobre a síntese de proteínas celulares. Os compostos, quando empregados nas concentrações antivirais ótimas, não afetam significativamente a síntese do ADN celular e são assim específicos inibidores da síntese de proteínas do retrovírus. A infecção viral é então inibida, enquanto o crescimento celular permanece inalterado.

\section{TIOSSEMICARBAZONAS E SEUS COMPLEXOS METÁLICOS COM ATIVIDADE ANTIMICROBIANA}

\section{Tiossemicarbazonas com atividade antibacteriana, antifúngica e antiparasitária}

Tiossemicarbazonas e seus complexos metálicos apresentam um amplo espectro de atividades antimicrobianas e este assunto foi tratado em artigo que escrevemos previamente ${ }^{4}$. Aqui caberia comentar que, de modo geral, as tiossemicarbazonas, em particular as $\alpha(\mathrm{N})$ heterocíclicas e seus complexos metálicos, inibem o crescimento de bactérias gram positivas, tais como Neisseria gonorrhoeae, Neisseria meningitides, Staphylococcus faecalis, Streptococcus faecalis e D Enterococcus, mas não são bons inibidores de bactérias gram negativas tais como Pseudomonas, Klebsiella-Enterobacter, Shigella, Escherichia coli e Proteus ${ }^{76}$.

A atividade dessa classe de compostos e seus complexos contra diferentes culturas de fungos tais como Macrophomina phaseolina, Fusarium oxysporum, Aspergillus niger, Amathia alternata, Paecilomyces variotii e outras, foi e continua sendo amplamente investigada na literatura ${ }^{4,77}$.

Em muitos casos a atividade aumenta pela coordenação aos cátions metálicos, provavelmente porque a lipofilia se altera pela complexação. Por outro lado, pode-se imaginar que o mecanismo de ação possa ocorrer através da coordenação de metais presentes na estrutura de enzimas necessárias ao microorganismo. Uma estratégia possível na concepção de novos agentes antifúngicos e antibacterianos seria a de aliar propriedades biológicas dos ligantes àquelas dos metais. Como exemplos podemos citar a obtenção de complexos com oxovanádio(IV), ativos como antibacterianos ${ }^{78}$ ou de estanho(IV), ativos como antifúngicos ${ }^{52}$.

A complexação com sais de butilestanho, de algumas tiossemicarbazonas ativas contra Candida albicans, levou a uma diminuição ou perda da atividade, com uma piora na ação antifúngica à medida que se aumentava o número de grupos butila, possivelmente porque os complexos formados seriam demasiadamente volumosos, dificultando assim sua passagem através da membrana celular ${ }^{79}$.

Consideramos de interesse mencionar aqui resultados recentes de atividade de complexos de bismuto(III) com tiossemicarbazonas que inibiram in vitro o crescimento de Helicobacter pylori, a bactéria causadora de úlcera ${ }^{80}$, e tiossemicarbazonas derivadas de tiofeno que apresentaram atividade amebicida, a qual aumenta pela complexação ao rutênio ou à platina ${ }^{81}$. A possibilidade de uso clínico desses complexos parece remota em razão de seu alto custo e do fato de se tratar de doenças negligenciadas, mas a investigação se mostra relevante já que o metronidazol, comumente usado, mostrou ter efeito carcinogênico e mutagênico.

\section{Tiossemicarbazonas com atividade antituberculose}

Apesar dos inúmeros esforços feitos em pesquisa em todo o mundo, a tuberculose é a principal causa de morte e sofrimento devidos a uma única entidade infecciosa. Estima-se que aproximadamente um terço da população mundial esteja infectada com o bacilo Mycobacterium tuberculosis ${ }^{82}$. Um fator agravante dessa situação é o aparecimento de uma epidemia de tuberculose resistente à medicação.
Virtualmente todos os agentes antituberculose usados atualmente foram desenvolvidos nos anos 40-5082. Já em 1946, Domagk relata que algumas tiossemicarbazonas possuíam atividade antituberculose in vitro e a atividade se manifestava in vivo em alguns casos ${ }^{63}$. Desde então foram testadas as atividades de séries de semi e tiossemicarbazonas com diferentes características estruturais ${ }^{83}$, procurando-se estabelecer os requerimentos necessários à atividade. A ação manifesta-se principalmente em tiossemicarbazonas derivadas de benzaldeídos com substituintes em posição para ou de aldeídos heterocíclicos. A atividade dentro de uma serie de acetilpiridina tiossemicarbazonas N(4)-substituídas depende de o composto apresentar um caráter hidrofóbico ótimo, o qual controlaria sua passagem através da membrana celular ${ }^{83}$.

O único composto da classe a ser empregado clinicamente é a 4acetamidobenzaldeído tiossemicarbazona (Figura 5a), comercialmente conhecido como tiacetazona. Entretanto, sua ação predominantemente bacteriostática in vivo e o rápido aparecimento de cepas resistentes à tiacetazona ${ }^{84}$ durante o tratamento, além de efeitos colaterais importantes, como a indução de diabetes melitus, limitam sua utilização.

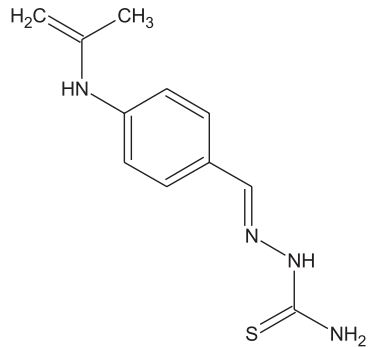

(a)

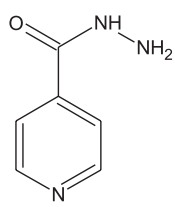

(b)
Figura 5. Compostos com atividade antituberculose: (a) 4-acetamidobenzaldeído tiossemicarbazona (tiacetazona); (b) isoniazida

Nos países africanos, em razão da epidemia de AIDS, a tiacetazona é usada ainda hoje ${ }^{85}$, principalmente em associação com a isoniazida (Figura 5b), para obtenção de efeitos sinergísticos e de reversão da resistência. Do mesmo modo, a literatura relata que o uso combinado de tiacetazona com rifampicina, além de melhorar as propriedades de permeação das drogas, pode levar ao sinergismo ${ }^{86}$.

O mecanismo de ação da tiacetazona é ainda desconhecido, mas, uma vez que cepas resistentes à tiossemicarbazona apresentam resistência cruzada à etionamida (uma droga de segunda geração) ${ }^{84}$, e que o modo de ação da etionamida se dá através da inibição da biosssíntese do ácido micólico envolvido na formação da parede celular do bacilo, um mecanismo semelhante poderia ser proposto para a ação da tiacetazona.

O complexo de cobre(II) da tiacetazona mostrou-se mais ativo do que o ligante livre. Um mecanismo envolvendo reações de transferência de elétrons e stress oxidativo foi proposto, no qual um complexo de cobre(II) da droga com o ADN efetuaria transferência de elétrons para o oxigênio, produzindo oxo-espécies tóxicas que destruiriam o invasor ${ }^{87}$.

Para se obter compostos com maior caráter lipofílico, tiossemicarbazonas contendo uma variedade de substituintes no nitrogênio terminal da cadeia foram preparadas, bem como seus complexos com diferentes cátions metálicos ${ }^{88}$. No entanto, testes de atividade in vitro contra cepas sensíveis e resistentes de Micobacterium tuberculosis e Micobacterium bovis revelaram que os ligantes são inativos $^{89}$. 
Dois trabalhos recentes sobre compostos antituberculose devem ser citados nesta revisão. No primeiro, um modelo de farmacóforo foi desenvolvido, o qual foi capaz de identificar compostos pertencentes às classes de moléculas com atividade comprovada ${ }^{84}$. $\mathrm{O}$ segundo sugere que, com o final do mapeamento do genoma do Micobacterium tuberculosis, se faça uso da química genômica e da química combinatória no desenvolvimento de novas drogas eficientes em isolados com resistência múltipla ${ }^{82}$.

\section{OUTRAS POSSIBILIDADES FARMACOLÓGICAS DAS TIOSSEMICARBAZONAS}

Caberia aqui mencionar a possibilidade de uso de complexos de tiossemicarbazonas como radiofármacos, tanto para fins de diagnóstico como para radioterapia ${ }^{4}$. Finalmente, há ainda exemplos de complexos de tiossemicarbazonas que mimetizam a ação de certas enzimas, como alguns de cobre(II) que imitam a ação da superóxido dismutase $^{90}$.

\section{A VERSATILIDADE FARMACOLÓGICA DAS SEMICARBAZONAS}

Semicarbazonas são compostos que também apresentam amplo perfil farmacológico, embora muitas das atividades observadas para as tiossemicarbazonas se percam ou sofram diminuição pela substituição do enxofre por oxigênio. Entre outras, semicarbazonas mostram atividade como agentes antichagásicos, anticonvulsivantes, hipnóticos, pesticidas e herbicidas ${ }^{4}$.

\section{SEMICARBAZONAS COM ATIVIDADE ANTICONVULSIVANTE}

A epilepsia é uma das afecções mais comuns do sistema nervoso central e atinge cerca de $1 \%$ da população mundial. Trata-se de um distúrbio crônico, com crises recorrentes provocadas por uma excessiva descarga dos neurônios ${ }^{91}$. Aproximadamente $25 \%$ dos pacientes epilépticos apresentam crises não controladas pela medicação disponível na clínica, e muitas das drogas anticonvulsivantes provocam efeitos colaterais adversos que limitam sua utilização ${ }^{92}$. Desse modo, o desenho de novos anticonvulsivantes constitui área de grande interesse na pesquisa de fármacos.

Entre os modelos experimentais de epilepsia, podem-se citar o modelo do eletrochoque ("MES, maximum electroshock screen"), no qual as crises são induzidas por corrente elétrica, e o modelo químico, em que crises são provocadas por drogas pró-convulsivantes, como o pentilenotetrazol administrado sub-cutâneo. O primeiro modelo serve na identificação de drogas eficazes contra crises tônico-clônicas generalizadas ("grand mal") e o segundo, na identificação de drogas efetivas contra crises de ausência, ou "petit mal" ${ }^{33}$. No primeiro, os requerimentos necessários à atividade são a presença de dois átomos doadores de elétrons próximos a um grupo hidrofóbico volumoso. No segundo, é necessário igualmente haver dois átomos doadores de elétrons, que devem estar próximos a um grupo menor e menos hidrofóbico do que no caso da atividade no teste do eletrochoque ${ }^{93}$. As drogas mais comumente usadas clinicamente são a fenitoína, a carbamazepina, o fenobarbital e o valproato. As três primeiras possuem os requisitos estruturais necessários à atividade em crises generalizadas, e o valproato, com estrutura inteiramente distinta, mostra-se mais ativo nas crises de ausência.

Recentemente uma grande variedade de semicarbazonas, como aquelas contendo grupos arila, arilideno, ariloxi(aril $)^{93-100}$, ou as derivadas de isatina ${ }^{101}$ e muitas outras têm sido investigadas quanto à ação anticonvulsivante. Esses compostos, assim como muitas das drogas usadas na clínica, apresentam os requisitos estruturais necessários à atividade, mas não contêm a função dicarboximida (CONRCO), a qual pode contribuir para o aparecimento de efeitos tóxicos ${ }^{93}$.

De modo geral, observa-se que as semicarbazonas apresentam maior atividade no modelo do eletrochoque do que no do pentilenotetrazol sub-cutâneo. Quando administradas a camundongos por via intraperitonial são menos ativas e apresentam maior neurotoxidez do que quando administradas a ratos por via oral ${ }^{93-99}$. Vários estudos de relações estrutura-atividade, realizados principalmente por Dimmock e colaboradores, foram relatados na literatura. Assim, partindo-se do membro mais simples da série de aril semicarbazonas, a benzaldeído semicarbazona (BS, Figura 6a), foram feitas várias modificações estruturais, tais como a obtenção de um derivado contendo um bromo em posição $\operatorname{para}^{94}$, ou a síntese de derivados nos quais a cadeia lateral não está livre para girar, ou seja, apresentam conformações "congeladas" "96, e ainda derivados contendo espaçadores em diferentes posições ${ }^{97}$ (ver Figura 6b-d).

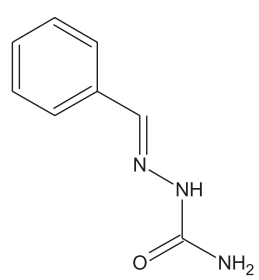

(a)

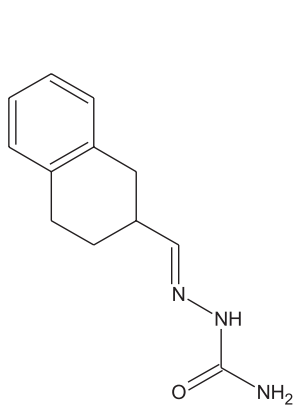

(c)

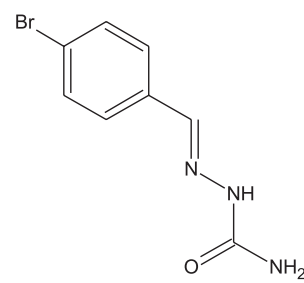

(b)

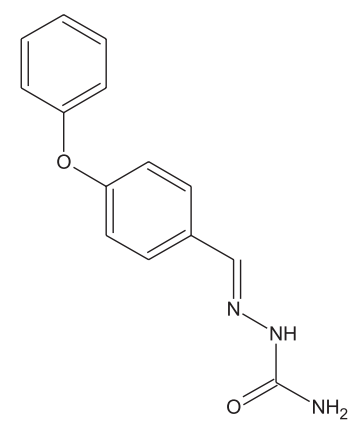

(d)
Figura 6. Estruturas de semicarbazonas com atividade anticonvulsivante: (a) benzaldeído semicarbazona (BS); (b) para-bromobenzaldeído semicarbazona; (c) 2-tetralona semicarbazona e (d) ariloxi(aril)-benzaldeído semicarbazona

A 4-bromobenzaldeído semicarbazona (Figura 6b) foi escolhida como protótipo pelo "National Institute of Health (NIH)" americano e foi protegida por patente ${ }^{94,95}$. O composto não apresenta propriedades pró-convulsivantes e não foi observado o aparecimento de tolerância após sua administração em ratos por um longo período de tempo.

Aril semicarbazonas contendo grupos ariloxi como espaçadores em posição para (Figura 6d) mostraram-se muito ativas como anticonvulsivantes ${ }^{97}$. Alguns membros da série, quando administrados oralmente em ratos, apresentaram índices de proteção e potências maiores do que fenitoína e carbamazepina no teste do eletrochoque. Espaçadores em orto resultaram em compostos menos ativos, sugerindo uma intolerância espacial para estas estruturas. Por outro lado, aril semicarbazonas com estruturas rígidas, nas quais a cadeia lateral não pode girar (Figura 6c), mostraram, em alguns casos, maior ativi- 
dade e maior índice de proteção e, em outros, a modificação estrutural não trouxe benefícios ${ }^{96}$.

Acredita-se que as semicarbazonas devam interagir em dois locais no receptor: uma área de ligações de hidrogênio e um domínio hidrofóbico ${ }^{96,97}$. O mecanismo de ação desses compostos é ainda assunto de investigação. Alguns deles interferem com a ligação de bicuculina aos receptores do ácido $\gamma$-amino-butírico, o GABA, e outros com a ligação de picrotoxina aos canais de cloreto, sugerindo que esses seriam possíveis mecanismos ${ }^{93}$. 4-bromobenzaldeído semicarbazona, no entanto, apesar de aparentemente interagir com receptores de GABA nos canais de cloreto, apresenta um fraco efeito antagonista de GABA e pareceria ter assim um mecanismo de ação diferente do da maioria dos anticonvulsivantes em uso clínico ${ }^{94}$.

Um terceiro modelo experimental, menos comum, é o modelo audiogênico, no qual uma colônia de ratos WAR ("wistar audiogenic rats") é geneticamente selecionada para apresentar crises convulsivas quando os animais são submetidos a um som de alta intensidade $(120 \mathrm{~dB})$. O modelo aproxima-se mais da condição dos pacientes epilépticos, uma vez que os animais já nascem com a característica de apresentar convulsões. Nossos testes de atividade de benzaldeído semicarbazona (BS, Figura 6a) revelaram que o composto é também ativo nesse terceiro modelo, como mostrado na Figura $7^{102}$.

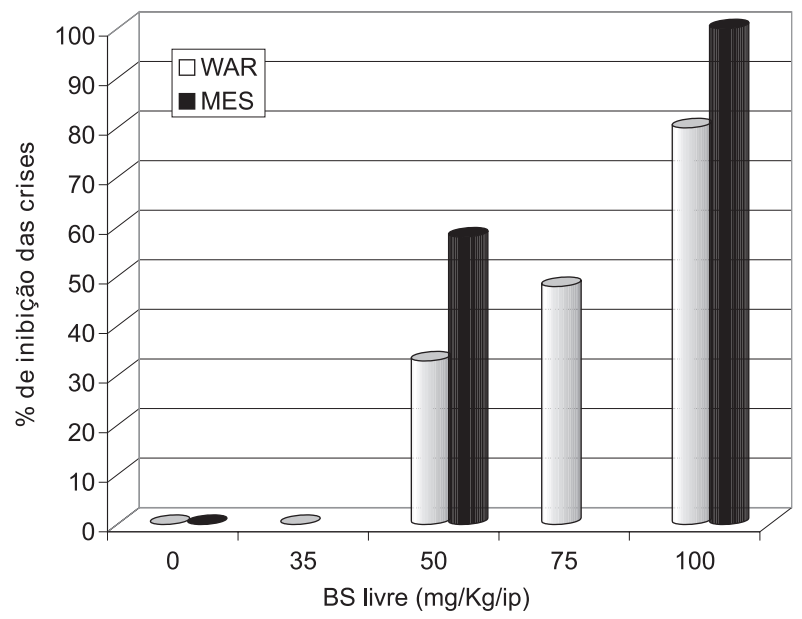

Figura 7. Atividade anticonvulsivante de benzaldeído semicarbazona (BS) no modelo do eletrochoque (MES) e no modelo audiogênico (WAR)

Em seguida, passamos à preparação de novas formulações farmacêuticas que pudessem permitir um aumento da biodisponibilidade da semicarbazona, com abaixamento da dose, diminuindo assim efeitos colaterais indesejáveis. Para isso, empregando a estratégia hospedeiro-convidado ("host-guest"), preparamos compostos de inclusão de BS em $\beta$-ciclodextrina $(\beta-C D)$ e em hidroxipropil- $\beta$ ciclodextrina (HP- $\beta-C D)$, os quais foram testados quanto à atividade anticonvulsivante no modelo do eletrochoque e no modelo audiogênico ${ }^{102}$.

O BS livre, na dose de $100 \mathrm{mg} / \mathrm{kg}$, quando administrado intraperitonial ou via oral, bloqueia $90 \%$ das crises, e o composto de inclusão BS/HP- $\beta$-CD $100 \%$. A $50 \mathrm{mg} / \mathrm{kg}$, a droga livre bloqueia $50 \%$ das crises, enquanto que o composto de inclusão continua bloqueando $100 \%$. Em $35 \mathrm{mg} / \mathrm{kg}$ o composto de inclusão ainda bloqueia $100 \%$ e em $25 \mathrm{mg} / \mathrm{kg}$ inibe mais de $60 \%$ das crises (Figura 8), indicando um abaixamento de $75 \%$ na dose, decorrente de significativo aumento da biodisponibilidade pela inclusão na ciclodextrina. No modelo audiogênico foi observada uma redução da dose de $65 \%{ }^{102}$. A inclusão em $\beta-C D$ resultou em um anticonvulsivante ainda mais eficaz, com o abaixamento da dose de $100 \mathrm{mg} / \mathrm{kg} / \mathrm{ip}$ ou vo no BS livre para $25 \mathrm{mg} / \mathrm{kg} / \mathrm{ip}$ no composto de inclusão, para o bloqueio total das convulsões, e para $15 \mathrm{mg} / \mathrm{kg} / \mathrm{ip}$ no composto de inclusão para uma inibição de $60 \%$ das convulsões (Figura 8). A inclusão na $\beta$-CD apresenta a vantagem adicional de ser mais adequada para formulações orais ${ }^{103}$.

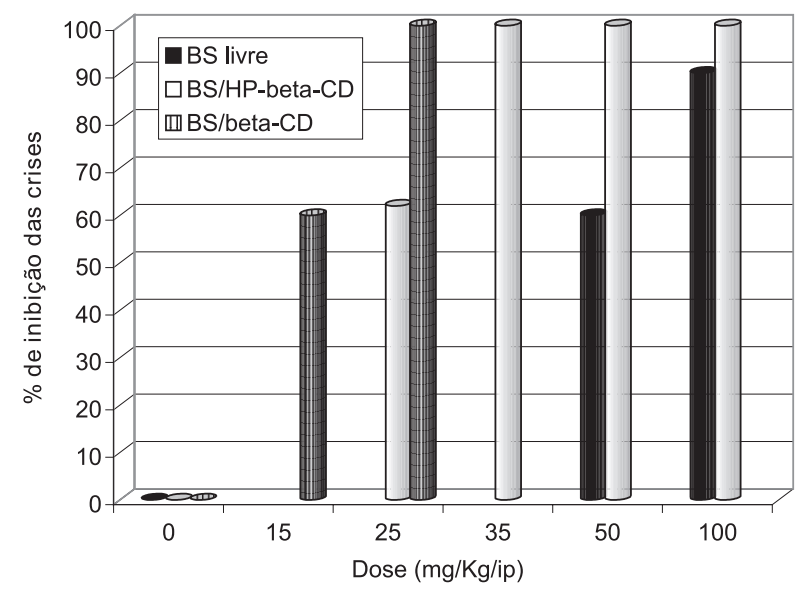

Figura 8. Efeito anticonvulsivante de benzaldeído semicarbazona (BS) livre e das formulações BS/HP- $\beta$-CD e BS/ $\beta$-CD no modelo do eletrochoque (MES)

\section{SEMICARBAZONAS COM ATIVIDADE ANTICHAGÁSICA}

Trypanossoma cruzi é o agente etiológico da doença de Chagas, um mal que afeta 16 a 18 milhões de pessoas, com mais de 45000 mortes/ano ${ }^{104}$. A quimioterapia disponível contra a doença é ainda inadequada, já que as drogas comumente usadas, Nifurtimox ${ }^{\circledR} \mathrm{e}$ Benznidazol $^{\circledR}$, apresentam efeitos colaterais indesejáveis e são ineficientes no tratamento da doença crônica ${ }^{104}$.

O metabolismo de tripanotiona pode ser visto como um alvo, uma vez que não ocorre em células de mamíferos, mas é essencial para a sobrevivência do parasita. O planejamento de agentes antichagásicos leva em consideração a eventual capacidade dos compostos de funcionarem como substratos da tripanotiona redutase. Entre os de melhor perfil farmacológico podem ser mencionadas semicarbazonas análogas à Nifurtimox e semicarbazonas derivadas de heterociclos que contêm a função $N$-óxido ${ }^{104}$.

\section{OUTRAS POSSIBILIDADES FARMACOLÓGICAS DAS SEMICARBAZONAS E SEUS COMPLEXOS METÁLICOS}

Há outras propriedades farmacológicas relevantes das semicarbazonas, como o efeito inibitório da produção de NO por 1,2-naftoquinona-2-semicarbazona (naftazona). Estudos demonstraram que a administração aguda e crônica de naftazona em ratos provoca a redução da pressão portal, mas a pressão arterial não varia apreciavelmente, sugerindo o interesse da investigação de possíveis aplicações das semicarbazonas nessa área ${ }^{105}$. Finalmente, seria interessante mencionar a atividade de alguns complexos de cobre(II) de semicarbazonas como mimetizadores da superóxido dismutase ${ }^{106}$.

\section{CONCLUSÕES}

Tiossemicarbazonas e semicarbazonas mostram assim uma grande versatilidade farmacológica. Entre as razões estruturais que explicariam esse amplo perfil estão o fato de serem esses compostos 
bons agentes quelantes, podendo coordenar-se a metais existentes nas estruturas de enzimas, inativando-as, bem como a possibilidade de modular-se o caráter lipofílico dessas moléculas assim como suas interações com receptores biológicos, através da escolha dos substituintes da cadeia. Finalmente, o enxofre com caráter de tiol nas tiossemicarbazonas pode se envolver em reações redox dentro do organismo.

\section{AGRADECIMENTOS}

Agradeço aos meus alunos de Pós-Graduação e Iniciação Científica, sem os quais a contribuição de nosso grupo para esta área de investigação não teria sido possível. Agradeço também a valiosa contribuição de todos os meus colaboradores, cujos nomes aparecem nas referências, e o financiamento desta pesquisa pelas agências CNPq, Capes e Fapemig.

\section{REFERÊNCIAS}

1. Farrel, N.; Coord. Chem. Rev. 2002, 232, 1.

2. Orvig, C.; Abrams, M. J.; Chem. Rev. 1999, 99, 2201.

3. Basolo, F.; Coord. Chem. Rev. 1993, 125, 13.

4. Beraldo, H.; Gambino, D.; Mini-Rev. Med. Chem. 2004, 4, 31.

5. West, D. X.; Liberta, A.; Padhye, S. B.; Chikate, R. C.; Sonawane, P. B.; Kumbhar, A. S.; Yerande, R. G.; Coord. Chem. Rev. 1993, 123, 49.

6. Brockman, R. W.; Thomson, J. R.; Bell, M. J.; Skipper, H. E.; Cancer Res. 1956, 16, 167.

7. French, F. A.; Blanz Jr., E. J.; Cancer Res. 1965, 25, 1454; French, F. A.; Blanz, Jr. E. J.; J. Med. Chem. 1966, 9, 585.

8. Moore, E. C.; Zedeck, M. S.; Agrawal, K. C.; Sartorelli, A. C.; Biochemistry 1970, 9, 4492.

9. Sartorelli, A. C.; Agrawal, K. C.; Moore, E. C.; Biochem. Pharmacol. 1971, $20,3119$.

10. Nocentini, G.; Crit. Rev. Oncol./Hematol. 1996, 22, 89.

11. Sartorelli, A. C.; Agrawal, K. C.; Tsiftsoglou, A. S.; Moore, E. C.; Adv. Enz. Reg. 1977, 15, 117.

12. Brockman, R. W.; Sidwell, R. W.; Arnett, G.; Shaddix, S. M.; Proc. Soc. Exp. Biol. Med. 1970, 133, 609.

13. Thelander, L.; Larson, B.; Hobbs, J.; Eckstein, F.; J. Biol. Chem. 1976, $251,1398$.

14. Antholine, W.; Knight, J.; Whelan, H.; Petering, D. H.; Mol. Pharmacol. 1977, 13, 89.

15. Ankel, E.; Petering, D. H.; Biochem. Pharmacol. 1980, 29, 1833.

16. Saryan, L. A.; Ankel, E.; Krishnamurti, C.; Petering, D. H.; J. Med. Chem. 1979, 22, 1218.

17. Preidecker, P. J.; Agrawal, K. C.; Sartorelli, A. C.; Colleen-Moore, E.; Mol. Pharmacol. 1980, 18, 507 e referências desse artigo.

18. Antholine, W.; Knight, J.; Whelan, H.; Petering, D. H.; J. Med. Chem. 1976, $19,339$.

19. Thelander, L.; Graslund, A.; J. Biol. Chem. 1983, 286, 4063; Thelander, L.; Graslund, A.; Thelander, M.; Biochem. Biophys. Res. Commun. 1983, $110,859$.

20. Beraldo, H.; Tosi, L.; Journal of the Royal Netherlands Chemical Society 1987, 106, 390; Borges, R. H.; Abras, A.; Beraldo, H.; J. Braz. Chem. Soc. 1997, 8,1 .

21. Beraldo, H.; Fantini, E.; Borges, R. H. U.; Rocha, M. A.; Tosi, L.; Abras, A.; Inorg. Chim. Acta 1990, 172, 113.

22. Borges, R. H. U.; Paniago, E.; Beraldo, H.; J. Inorg. Biochem. 1997, 65, 267.

23. Garcia-Tojal, J.; García-Orad, A.; Serra, J. L.; Pizarro, J. L.; Lezama, L.; Arriortua, M. I.; Rojo, T.; J. Inorg. Biochem. 1999, 75, 45.

24. Garcia-Tojal, J.; García-Orad, A.; Alvarez-Díaz, A.; Serra, J. L.; Urtiaga, M. K.; Arriortua, M. I.; Rojo, T.; J. Inorg. Biochem. 2001, 84, 271.

25. DeConti, R. C.; Toftness, B. R.; Agrawal, K. C.; Tomchick, R.; Mead, J. A. R.; Bertino, J. R.; Sartorelli, A. C.; Creasey, W.; Cancer Res. 1972, 32, 1455.

26. Agrawal, K. C.; Lin, A. J.; Booth, B. A.; Wheaton, J. R.; Sartorelli, A. C.; J. Med. Chem. 1974, 17, 631; Agrawal, K. C.; Lin, A. J.; Booth, B. A.; Denuzzo, S. M.; Sartorelli, A. C.; J. Med. Chem. 1975, 18, 368.

27. Agrawal, K. C.; Mooney, P. D.; Sartorelli, A. C.; J. Med. Chem. 1976, 19, 970.

28. Liu, M. C.; Lin, T. S.; Cory, J. G.; Cory, A. H.; Sartorelli, A. C.; J. Med. Chem. 1996, 39, 2586.

29. Finch, R. A.; Liu, M. C.; Cory, A. H.; Cory, J. G.; Sartorelli, A. C.; Adv. Enz. Reg. 1999, 39, 3.
30. Finch, R. A.; Liu, M. C.; Grill, S. P.; Rose, W. C.; Loomis, R.; Vasquez, K.; Cheng, Y.; Sartorelli, A. C.; Adv. Biochem Pharmacol. 2000, 59, 983.

31. Rappa, G.; Lorico, A.; Liu, M. C.; Kruh, G. D.; Cory, A. H.; Cory, J. G.; Sartorelli, A. C.; Biochem. Pharmacol. 1997, 54, 649.

32. Richardson, D. R.; Crit. Rev. Oncol./Hematol. 2002, 42, 267.

33. Petering, H. G.; Buskirk, H. H.; Underwood, G. E.; Cancer Res. 1964, 24, 367.

34. Petering, H. G.; Buskirk, H. H.; Crim, J. A.; Cancer Res. 1967, 27, 1115.

35. Crim, J. A.; Petering H. G.; Cancer Res. 1967, 27, 1278.

36. Booth, B. A.; Sartorelli, A. C.; Mol. Pharmacol. 1967, 3, 290.

37. Rodriguez-Arguelles, M. C.; Ferrari, M. B.; Fava, G. G.; Pelizzi, C.; Tarasconi, P.; Albertini, R.; Dall'Aglio, P.; Lunghi, P.; Pinelli, S.; J. Inorg. Biochem. 1995, 58, 157.

38. Hall, I. H.; Lackey, C. B.; Kistler, T. D.; Ives, J. S.; Beraldo, H.; Ackerman, L.; West, D. X.; Arch. Pharm. Pharm. Med. Chem. 2000, 333, 217.

39. Matesanz, A. I.; Pérea, J. M.; Navarro, P.; Moreno, J. M.; Colacio, E.; Souza, P.; J. Inorg. Biochem. 1999, 76, 29.

40. Wong, E.; Giandomenico, C.; Chem. Rev. 1999, 99, 2451.

41. Quiroga, A. G.; Perez, J. M.; Montero, E. I.; Masaguer, J. R.; Alonso, C.; Navarro-Ranninger, C.; J. Inorg. Biochem. 1998, 70, 117.

42. Quiroga, A. G.; Perez, J. M.; Lopez-Solera, I.; Montero, E. I.; Masaguer, J. R.; Alonso, C.; Navarro-Ranninguer, C.; J. Inorg. Biochem. 1998, 69, 275; Quiroga, A. G.; Perez, J. M.; Lopez-Solera, I.; Masaguer, J. R.; Luque, A.; Ronam, P.; Edwards, A.; Alonso, C.; Navarro-Ranninguer, C.; J. Med. Chem. 1998, 41, 1399.

43. Quiroga, A. G.; Perez, J. M.; Montero, E. I.; West, D. X.; Alonso, C.; Navarro-Ranninger, C.; J. Inorg. Biochem. 1999, 75, 293.

44. Mendes, I. C.; Teixeira, L. R.; Lima, R.; Beraldo, H.; Transition Met. Chem. 1999, 24, 655

45. Kovala-Demertzi, D.; Miller, J. R.; Koukoumelis, N.; Hadjikakou, S. K.; Demetzis, M. A.; Polyhedron 1999, 18, 1005.

46. Kovala-Demertzi, D.; Domopoulou, A.; Demetzis, M. A.; Papageorgiou, A.; West, D. X.; Polyhedron 1997, 16, 3625.

47. Gielen, M.; Coord. Chem. Rev. 1996, 151, 41.

48. Penninks, A. H. Em Tin-Based Antitumor Drugs; Gielen, M., ed.; NATO ASI Series, Serie H, Springer, Berlin, 1990, vol. 37, p.169-190.

49. Casas, J. S.; García-Tasende, M. S.; Maichle-Mössmer, C.; RodriguezArgüelles, M. C.; Sanchez, A.; Sordo, J.; Vasquez-Lopez, A.; Pinelli, S.; Lunghi, P.; Albertini, R.; J. Inorg. Biochem. 1996, 62, 41.

50. Casas, J. S.; Castiñeras, A.; Rodriguez-Argüelles, M. C.; Sanchez, A.; Sordo, J.; Vasquez-Lopez, A.; Pinelli, S.; Lunghi, P.; Caincianaini, P.; Bonati, A.; Dall'Aglio, P.; Albertini, R.; J. Inorg. Biochem. 1999, 76, 277.

51. Casas, J. S.; Rodriguez-Argüelles, M. C.; Russo, U.; Sanchez, A.; Sordo, J.; Vasquez-Lopez, A.; Pinelli, S.; Lunghi, P.; Bonati, A.; Albertini, R.; J. Inorg. Biochem. 1998, 69, 283 e referências desse artigo.

52. Teoh, S. G.; Ang, S. G.; Fun, H. K.; Ong, C. W.; J. Organomet. Chem. 1999, 580, 17.

53. Clarke, M. J.; Zhu, F.; Frasca, D. R.; Chem. Rev. 1999, 99, 2511.

54. Ferrari, M. B.; Fava, G. G.; Tarasconi, P.; Albertini, R.; Pinelli, S.; Starcich, R.; J. Inorg. Biochem. 1994, 53, 13.

55. Ferrari, M. B.; Fava, G. G.; Leporati, E.; Pelosi, G.; Rossi, R.; Tarasconi, P.; Albertini, R.; Bonatti, A.; Lunghi, P.; Pinell, S.; J. Inorg. Biochem. 1998, $70,145$.

56. Ferrari, M. B.; Bisceglie, F.; Pelosi, G.; Sassi, M.; Tarasconi, P.; Cornia, M.; Capacchi, S.; Albertini, R.; Pinelli, S.; J. Inorg. Biochem. 2002, 90, 113.

57. Ferrari, M. B.; Bisceglie, F.; Fava, G. G.; Pelosi, G.; Tarasconi, P.; Albertini, R.; Pinelli, S.; J. Inorg. Biochem. 2002, 89, 36.

58. Ferrari, M. B; Capacchi, S.; Reffo, G.; Pelosi, G.; Tarasconi, P.; Albertini, R.; Pinelli, S.; Lunghi, P.; J. Inorg. Biochem. 2000, 81, 36.

59. Marugkar, A.; Padhye, S.; Guha-Roy, S.; Wagh, U.; Inorg. Chem. Commun. 1999, 2, 545.

60. Pérez, J. M.; Matesanz, A. I.; Martin-Ambite, A.; Navarro, P.; Alonso, C.; Souza, P.; J. Inorg. Biochem. 1999, 75, 255.

61. Arion, V. B.; Jakupec, M. A.; Galanski, M.; Unfried, P.; Keppler, B. K.; J. Inorg. Biochem. 2002, 91, 298.

62. Seligman, P. A.; Crawford, E. D.; J. Natl. Cancer Inst. 1991, 83, 1582.

63. Domagk, G.; Behnish, R.; Mietzch, F.; Schmidt, H.; Naturwissenschaften 1946, 33, 315, Domagk, G.; Nordisk Medicin 1948, 39, 1322.

64. Hamre, D.; Bernstein, J.; Donovick, R.; Proc. Soc. Exp. Biol. Med. 1950, 73,275 .

65. Bauer, D. J.; Ann. N.Y. Acad. Sci. 1965, 130, 110; Bauer, D. J.; St. Vincent, L.; Kempe, C. H.; Downie, A. W.; Lancet 1963, 494; Bauer, D. J.; St. Vincent, L.; Kempe, C. H.; Young, P. A.; Downie, A. W.; Am. J. Epidemiol. 1969, 90, 130 .

66. Neyts, J.; De Clerq, E.; Antiviral Res. 2003, 57, 25.

67. Brockman, R. W.; Thompson, J. R.; Bell, M. J.; Skipper, H. E.; Cancer Res. 1956, 16, 167. 
68. Shipman, C.; Smith, S. H.; Drach, J. C.; Klayman, D.L.; Antiviral Res. 1986, 6, 197.

69. Ronen, D.; Nir, E.; Teitz, Y.; Antiviral Res. 1985, 5, 249.

70. Altun, A.; Kumru, M.; Dimoglo, A.; J. Mol. Struct. (Teochem.) 2001, 535, 235.

71. Louie, A. Y.; Meade, T. J.; Chem. Rev. 1999, 99, 2711

72. Turk, S. R.; Shipman, C. Jr.; Drach, J. C.; Biochem. Pharmacol. 1986, 35, 1539.

73. Field, H. J.; Reading, M. J.; Antiviral Res. 1987, 7, 245.

74. Easmon, J.; Heinish, G.; Holzer, W.; Rosenwith, B.; J. Med. Chem. 1992, $35,3288$.

75. Teitz, Y.; Ronen, D.; Vansover, A.; Stematsky, T.; Riggs, J. L.; Antiviral Res. 1994, 24, 305 e referências desse artigo.

76. Dobek, A. S.; Klayman, D. L.; Dickson Jr., E. T.; Scovil, J. P.; Tramont E. C.; Antimicrob. Agents Chemother 1980, 18, 27; Dobek, A. S.; Klayman, D. L.; Dickson Jr., E. T.; Scovil, J. P.; Tramont, E. C.; Oster, C. N.; Arzneim.-Forsch. 1983, 33, 1583; Klayman, D. L.; Lin, A. J.; Hosh, J. M.; Scovil, J. P.; Lambros, C.; Dobek, A. S.; J. Pharm. Sci. 1984, 73, 1763; Dobek, A. S.; Klayman, D. L.; Scovil, J. P.; Dickson Jr., E. T.; J. Chemotherapy 1986, 32, 25.

77. Singh, D.; Singh, R. V.; J. Inorg. Biochem. 1993, 15, 2; Ali, M. A.; Mirza, A. H.; Hossain, M. S.; Nazimudin, M.; Polyhedron 2001, 20, 1045.

78. Fahmi, N.; Singh, R. V.; J. Indian Chem. Soc. 1996, 73, 257.

79. Rebolledo, A. P.; de Lima, G. M.; Gambi, L. N.; Speziali, N. L.; Maia, D. F.; Pinheiro, C. B.; Ardisson, J. D.; Cortés, M. E.; Beraldo, H.; Appl. Organomet. Chem. 2003, 17, 145 .

80. Dittes, U.; Vogel, E.; Keppler, B.; Coord.Chem. Rev. 1997, 163, 345; Briand, G.; Bufford, N.; Chem. Rev. 1999, 99, 2601.

81. Shailendra, N. B.; Gonzalez Garza, M. T.; Cruz-Vega, D. E.; Castro Garza, J.; Saleem, K.; Naqvi, F.; Azam, A.; Bioorg. Med. Chem. Lett. 2001, 11 , 2675; Shailendra, N. B.; Naqvi, F. A.; Bioorg. Med. Chem. Lett. 2003, 13 , 689.

82. Barry, C. E.; Slayden, R. A.; Sampson, A. E.; Lee, R. E.; Biochem. Pharmacol. 2000, 59, 221.

83. Collins, F. M.; Klayman, D. L.; Morrison, N. E.; J. Gen. Microbiol. 1982, $128,1349$.

84. Manetti, F.; Corelli, F.; Biava, M.; Fioravanti, R.; Porretta, G. C.; Botta, M.; Il Fármaco 2000, 55, 484.

85. Abate, G.; Koivula, T.; Hoffner, S. E.; Int. Tuberc. Lung. Dis. 2002, 6, 933

86. Seydel, J. K.; Schaper, K. J.; Rush-Gerdes, S.; Immunobiology 1994, 191, 569.

87. Kovacic, P.; Ames, J. D.; Ryan, M. D.; Bioelectrochemistry and Bioenergetics 1989, 21, 269, a section of J. Electroanal. Chem. 1989, 275
88. Beraldo, H.; Nassar, A.; El Sayed, F.; Ayad, M. I.; West, D. X.;Transition Met. Chem. 1999, 24, 25; Beraldo, H.; Nassar, A.; El Sayed, F.; Ayad, M. I.; West, D. X.;Transition Met. Chem. 1999, 24, 421; Beraldo, H.; Nassar, A.; El Sayed, F.; Ayad, M. I.; West, D. X.;Transition Met. Chem. 1999, 24, 595.

89. Teixeira, L. R.; Salas, C.; Beraldo, H.; comunicação pessoal.

90. Diaz, A.; Cao, R.; Fragoso, A.; Sanchez, H.; Inorg. Chem. Commun. 1999, 2,358 .

91. Rang, H. P.; Dale, M. M.; Ritter, J. M.; Farmacologia, 3a ed., Ed. Guanabara Koogan, 1995, cap. 30, p. 474.

92. Sridhar, S. K.; Pandeya, S. N.; Stables, J. P.; Ramesh, A.; Eur. J. Med. Chem. 2002, 16, 129

93. Dimmock, J. R.; Sidhu, K. K.; Thayer, R. S.; Mack, P.; Duffy, M. J.; Reid, R. S.; Quail, J. W.; Pugazhenthi, U.; Ong, A.; Bikker, J. A.; Weaver, D. F.; J. Med. Chem. 1993, 36, 2244.

94. Dimmock, J. R.; Baker, G. B.; Epilepsia 1994, 35, 648

95. Dimmock, J. R.; Sidhu, K. K.; Tumber, S. D.; Basran, S. K.; Chen, M.; Quail, J. W.; Yang, J.; Rozas, I.; Weaver, D. F.; Eur. J. Med. Chem. 1995, $30,287$.

96. Dimmock, J. R.; Pandeya, S. N.; Quail, J. W.; Pugazhenthi, U.; Allen, T. M. Kao, G. Y.; Balzarini, J.; De Clerq, E.; Eur. J. Med. Chem. 1995, 30, 303.

97. Dimmock, J. R.; Puthucode, R. N.; Smith, J. M.; Hetherington, M.; Quail, J. W.; Pugazhenthi, U.; Lechler, T.; Stables, J. P.; J. Med. Chem. 1996, 39, 3984.

98. Puthucode, R. N.; Pugazhenthi, U.; Quail, J. W.; Stables, J. P.; Dimmock, J. R.; Eur. J. Med. Chem. 1998, 33, 595.

99. Dimmock, J. R.; Vashishtha, S. C.; Stables, J. P.; Eur. J. Med. Chem. 2000, $35,241$.

100. Pandeya, S. N.; Ponnilavarasan, I.; Pandeya, A.; Lahkan, R.; Stables, J. P.; Pharmazie 1999, 54, 923.

101. Pandeya, S. N.; Yogeeswary, P.; Stables, J. P.; Eur. J. Med. Chem. 2000, 35 , 879; Pandeya, S. N.; Raja, A. S.; Stables, J. P.; J. Pharm. Sci. 2002, 5, 266.

102. Beraldo, H.; Sinisterra, R. D.; Teixeira, L. R.; Vieira, R. P.; Doretto, M. C.; Biochem. Biophys. Res. Commun. 2002, 206, 241.

103. Teixeira, L. R.; Sinisterra, R. D.; Vieira, R. P.; Doretto, M. C.; Beraldo, H.; J. Incl. Phenom. Macrocyclic Chem. 2003, 47, 77.

104. Cerecetto, H.; Di Maio, R.; Ibarruri, G.; Seoane, G.; Denicola, A.; Quijano, A.; Peluffo, G.; Paulino, M.; Il Fármaco 1998, 53, 89; Cerecetto, H.; Di Maio, R.; González, M.; Risso, M.; Sagrera, G.; Seoane, G.; Denicola, A.; Peluffo, G.; Quijano, C.; Basombrio, M. A.; Paulino, M.; Olea-Azar, C.; Eur. J. Med. Chem. 2000, 35, 343.

105. Sogni, P.; Yang, S.; Pilette, C.; Moreau, R.; Gadano, A.; Avenard, G.; Bloy, C.; Lebrec, D.; Eur. J. Pharmacol. 1998, 344, 37.

106. Patole, J.; Dutta, S.; Padhye, S.; Sinn, E.; Inorg. Chim. Acta 2001, 318, 207. 